\title{
Binder Contribution to Cracking of a Lightly Trafficked Asphalt Pavement Made with Clear Binder
}

\author{
Khalid. Al-Shamsi and Hossam F. Hassan
}

\begin{abstract}
This paper reports the findings of a technical investigation on the role of clear asphalt binder in the development of extensive block cracking in a lightly trafficked colored pavement. Visual inspection of the pavement surface was carried out together with detailed laboratory investigation on the rheological characteristics of the binder. The results showed that the tested clear binder is extremely viscous and harder than any bitumen grade specified by ASTM standards. Furthermore, the clear binder has much lower ductility compared to the conventional asphalt bitumen. The clear binder is almost 11 times more viscous than the conventional bitumen at the tested temperatures.
\end{abstract}

Index Terms-Clear binder, block cracking, colored pavements, synthetic binders.

\section{INTRODUCTION}

Colored asphalt pavements are used in large public areas for aesthetic reasons. It is also used for safety reasons to deliver visual alert for drivers and pedestrians at complex intersections and dangerous roads. Coloring of asphalt mixtures is achieved by several ways including the use of colored aggregates and synthetic clear binders. In colored asphalt mixtures, clear binders replaces the conventional black bitumen. A clear binder is a synthetic binder with a brownish color, which, to some extent, have the properties of a conventional bitumen. The clear binders can be produced in different ways. Detailed information on the production and chemical nature of clear binders can be found in literature elsewhere $(1,2,3,4,5)$.

The relative transparency of these binders allows the natural color of mineral aggregates to be visible making the pavements take the color of the used aggregates. Clear binders can also be blended with pigments in the asphalt mixture to obtain specific colors. The introduction of clear binders and pigments in asphalt mixtures will definitely influence the characteristics of the mixture and ultimately its behavior in service. Limited research work have been done to investigate the effect of utilizing clear binders in asphalt mixtures. Plug and de Bondt [6] studied different aspects of clear binders in relation to standard penetration grade bitumen. Rheological properties (including stiffness characteristics from DSR testing) of three types of clear binders were determined and the results were compared with the requirement of a typical conventional bitumen. They concluded that clear binders behave in a similar way as a standard paving grade bitumen. In the same study, the performance of asphalt mixtures made with a polymer modified clear binder was evaluated and compared with a Dutch (SMA asphalt) reference mixture. For this purpose, a gyratory-compacted samples were prepared, which were tested after severe ageing for raveling and cracking resistance. The resistance against raveling was tested using the Cantabro device and cracking was checked using the indirect tensile test. Both tests were performed at $5{ }^{\circ} \mathrm{C}$. It was concluded that with the use of a proper mix design a colored asphalt pavement could be constructed with at least the same properties as a conventional black asphalt pavement.

Maurizio Boccia et al. [7] conducted a study on field specimens of a dense graded colored asphalt mixtures used as a wearing course in a tunnel in Italy. The mixture was produced in a mix-plant using dioritic coarse aggregate $(40 \%$ by aggregate weight), fine limestone aggregates ( $52 \%$ by aggregate weight), a specific filler ( $8 \%$ by aggregate weight) and a clear binder ( $5 \%$ by aggregate weight). A detailed laboratory characterization based on traditional and performance-based tests was conducted to assess the performance of the mixture. Preliminary volumetric analysis on Marshall and gyratory compacted specimens showed that the colored mixture has adequate compactability and showed a significant sensitivity to compaction energy similarly to traditional HMA. The stiffness properties at $20^{\circ} \mathrm{C}$ of the colored mixture were found comparable with that of an HMA for wearing courses denoting suitable performance for the specific use. The mixture also showed good moisture resistance when tested according to EN 12697-26 standard. The study suggests, however, that the colored mixture may have the tendency for plastic flow indicating a questionable permanent deformation resistance.

Santagata et.al [8] reported the results of an extensive study on the use of synthetic binders in wearing course mixes. In his study, open graded mixtures were prepared with a synthetic clear binder, some of which were reinforced with cellulose fibers, In particular, nine mixes, with different binder and cellulose fiber contents, were investigated through several laboratory tests to find the 'optimum' mixture in terms of both mechanical performance and durability. Marshall, Indirect Tensile and Cantabro tests were conducted on the mixtures. The performance of the mixtures made with the synthetic clear binder was compared with a traditional open graded mix (with SBS hard bitumen). The investigators reported that mixtures made with clear binder had a superior performance over the traditional mixture.

\section{OBJECTIVE}

The objective of this paper is to report the findings of a technical investigation on the role of clear asphalt binder in
Khalid. Al-Shamsi and Hossam. F. are with the Sultan Qaboos University, Department of Civil and Architectural Engineering, College of Engineering, Oman (e-mail: alshamsi@squ.edu.om, hossam@squ.edu.om). 
the development of extensive block cracking in a lightly trafficked colored pavement. Laboratory investigation on the rheological characteristics of the binder was carried out. In depth discussion of the results is provided.

\section{PAVEMENT StRUCTURE}

The surface of specific paved sections of a popular tourist area is showing cracks at different locations. The pavement is red colored and was constructed in 2006. The pavement structure consists of a bituminous surface layer, a granular base course, and a granular subbase course over a subgrade. The surface of the pavement structure is composed of $80 \mathrm{~mm}$ thick asphalt base course and $40 \mathrm{~mm}$ thick asphalt wearing course layers. The asphalt base course mixture is made of natural red colored aggregates obtained from a local query mixed with a standard 60/70 penetration grade bitumen that was blended with pigment of approximately $15 \%$ by weight of total mixture. The asphalt wearing course was also made of natural red colored aggregates but mixed with a type of clear binder obtained from a local supplier. Fig 1 shows the aggregate gradation of the asphalt surface and base course layers. The in situ air voids ranged from $9 \%-12 \%$ for the wearing surface layer and $15 \%-16 \%$ for the asphalt base layer. This level of air voids is considered extremely high for dense graded asphalt mixtures.

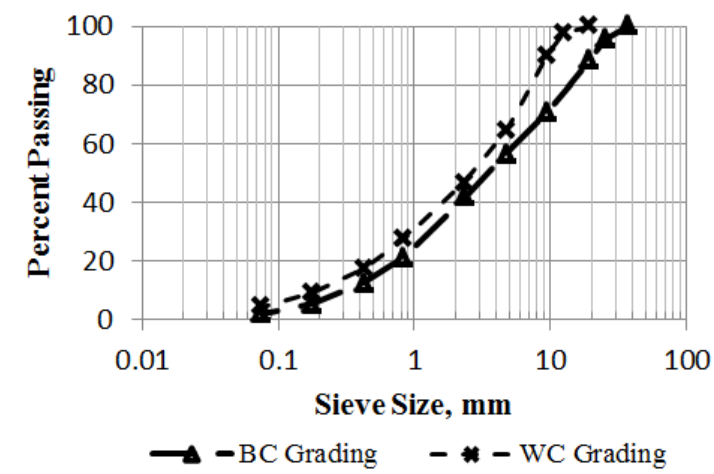

Fig. 1. Aggregate gradation of asphalt surface and base course layers.

A site visit to some affected areas revealed that the main type of cracks is block cracking. Some longitudinal cracks were also observed that appears to be along construction joints. Fig 2 shows some affected areas. Some weathering and raveling were also noticed which are also indicative of hardening of asphalt binder.

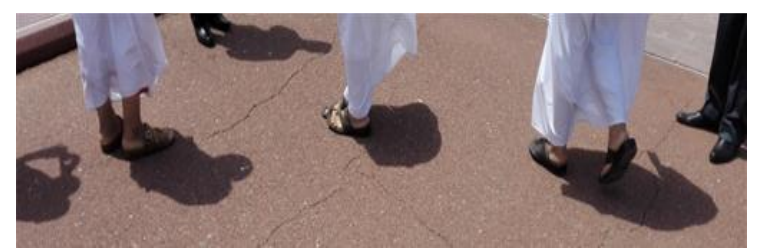

Fig. 2. Examples of the surface conditions observed in the affected pavement Sections.

\section{THEORETICAL BASIS OF THE STUDY}

Cracking is a pavement distress that affects the riding quality and the structural integrity of the pavement causing durability problems that eventually reduces the service life of the pavement. Block cracking is a non-load associated cracking, in which the pavements cracks in both longitudinal and transverse directions. The cracks become interconnected and the paved surface will be divided into a number of rectangular blocks. This type of cracks is usually non-load associated and caused by volume change or shrinkage in either the asphalt layer or the granular layers below it. Fine asphalt mixtures (that are generally used for aesthetic reasons) with stiff asphalt binder typically displays shrinkage or block cracking. Using excessively stiff binder that is more appropriate to highly trafficked roads on parking lots or low volume roads will increase the occurrence of such shrinkage cracks [9]. The asphalt mixtures on those types of surfaces do not have the benefits of traffic compactions during their service life and if they are not initially properly compacted, the binder in the mixture will oxidize, hardens, and becomes brittle. With the daily thermal contraction and expansion, the stiff binder does not have the ability to absorb the shrinkage stresses developed and ultimately breaks, leading to the appearance of cracks on the surface.

\section{LABORATORY CHARACTERIZATION OF CLEAR BINDER}

Based on the field visit and the nature of the cracks observed and the likelihood (from a theoretical point of view) that the binder could have played a significant role in the development of the cracks, it was decided to conduct a preliminary laboratory investigation to determine the basic rheological characteristics of the binder used in the pavement sections using some standard testing protocols that are well-known to the asphalt paving industry.

\section{A. Acquisition of Clear Binder Sample}

A five $\mathrm{kg}$ of the same type of clear binder used in the pavement sections under study was acquired from a local supplier. The sample was supplied in sealed metal containers. No data sheet was supplied with the sample. Visual inspection of the supplied binder showed that it is brownish in color and semi-solid at room temperature although it feels harder than the normal 60/70 pen bitumen when hand pressed. The binder was heated to obtain smaller samples for testing. It was observed that it takes a higher temperature to soften the clear binder to a pourable state compared to conventional bitumen. Fig 3 shows a small specimen of the clear binder (on the left) together with a conventional binder at room temperature. It was noticed that small cracks developed on the surface of the clear binder after cooling to room temperature. Cracks were not observed in the conventional bitumen.

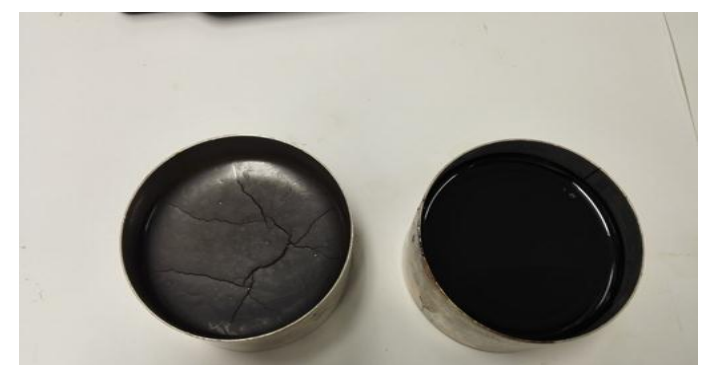

Fig. 3. Development of crack patterns in clear binder (on the left) cold specimen. 


\section{B. Testing Program}

In the absence of any technical data about the clear binder, a testing program was developed to determine some basic properties that influence the performance of the binder. The key properties that were assessed in this investigation were:

- Consistency (Penetration at $25^{\circ} \mathrm{C}$, and Softening Point)

- Viscosity (at a range of temperatures using the Brookfield Rotational Viscometer)

- Aging characteristics using RTFO (mass Loss, retained penetration)

- Ductility

Table 1 summarizes the laboratory tests conducted and the standards followed.

Consistency is the term used to describe the degree of fluidity or plasticity of binders at any particular temperature. The consistency of binder varies with temperature. In general, the higher the temperature, the lower the consistency will be (the softer the binder).

Viscosity is the resistance to flow of a fluid. The rotational viscometer has the capability to measure viscosity at a wide range of temperatures. This helps in determining the response of the binder to change in temperature. It is also used in checking the workability of the binder and its ability to be handled during mixing and compaction stages.

When the binder is exposed to air in thin films and is subjected to prolonged heating, i.e. during mixing with aggregates, the binder tends to harden. This process is termed as short-term aging. This phenomenon is manifested in the laboratory through the reduction in penetration value of the binder and the loss of mass due to the volatilization of light materials. A limited hardening is allowable. However, excessive hardening can seriously affect the durability of asphalt mixtures.

The ductility test method provides one measure of tensile properties of bituminous materials. The ductility is measured by the distance in centimeters that a standard briquette of asphalt cement will stretch before breaking when the two ends of the briquette specimen are pulled apart at a specified rate and temperature.

TABLE I: LABORATORY TESTS AND CORRESPONDING STANDARDS

\begin{tabular}{|l|l|}
\hline \multicolumn{1}{|c|}{ Laboratory Test } & Test Standard Designation \\
\hline $\begin{array}{l}\text { Standard Test Method for Penetration } \\
\text { of Bituminous Materials }\end{array}$ & ASTM D5/D5M-13 \\
\hline $\begin{array}{l}\text { Standard Test Method for Softening } \\
\text { Point of Bitumen (Ring-and-Ball } \\
\text { Apparatus) }\end{array}$ & ASTM D36/D36M-14 \\
\hline $\begin{array}{l}\text { Viscosity Determination of Asphalt } \\
\text { Binder Using Rotational Viscometer }\end{array}$ & AASHTO T 316-04 \\
\hline $\begin{array}{l}\text { Standard Test Method for Effect of } \\
\text { Heat and Air on a Moving Film of } \\
\text { Asphalt (Rolling Thin-Film Oven } \\
\text { Test) }\end{array}$ & ASTM D2872-12 \\
\hline $\begin{array}{l}\text { Standard Test Method for Ductility } \\
\text { of Bituminous Materials }\end{array}$ & ASTM D113-07 \\
\hline
\end{tabular}

\section{Results and Discussion}

The outcome of the testing program outlined in the previous section is summarized in Tables II and III and in Figs 4 \& 5 .

TABLE II: SUMMARY OF CONSISTENCY AND VISCOSITY TEST RESUlTS

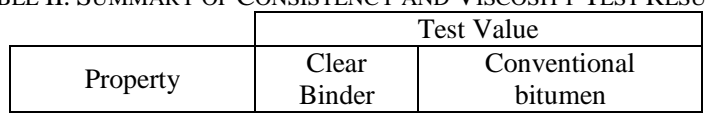

\begin{tabular}{|c|c|c|}
$\begin{array}{c}\text { Penetration at } 25 \\
\mathrm{C}(0.1 \mathrm{~mm})\end{array}$ & 34 & 49.5 \\
\hline $\begin{array}{c}\text { Softening Point, } \\
\mathrm{C}^{0}\end{array}$ & 68.5 & 51.5 \\
\hline $\begin{array}{c}\text { Viscosity at } 135 \\
\text { C, Pa.s }\end{array}$ & 4.4 & 0.39 \\
\hline $\begin{array}{c}\text { Viscosity at } 165 \\
\text { C, Pa.s }\end{array}$ & 1.131 & 0.108 \\
\hline
\end{tabular}

Table II presents the consistency and viscosity data for the original clear binder and the straight-run conventional bitumen that was obtained from a local supplier. The conventional bitumen has a penetration value of 49.5 which makes it fall in the hard category of bituminous binders. The data clearly indicates that the clear binder has a much harder consistency compared to the conventional one. A binder with a penetration value of 34 is considered extremely hard and actually harder than any grade specified by ASTM standards. The softening point of 68.5 is above the expected range for binders used for paving applications. The viscosity data also confirms this finding. The clear binder is almost 11 times more viscous than the conventional bitumen at the tested temperatures. More discussion on viscosity is presented later in this section.

The aging characteristics of the clear binder were investigated using the Rolling Thin Film Oven test (RTFO). RTFO procedure provides simulated short term aging for asphalt binder for physical property testing. Virgin asphalt binder is continuously exposed to heat and air flow to simulate the conditions of manufacturing and placement of asphalt mixture. Asphalt binders age primarily due to two different mechanisms: loss of light oils present in the asphalt (volatilization) and reaction with oxygen from the environment (oxidation). During manufacturing of asphalt mistures in the hot mixing facility and during lay down and construction, binders age due to both mechanisms because of the high temperature and air flow involved in the process. The rolling thin film oven (RTFO) is used to simulate this form of aging. Physical properties of the binder before and after the aging process are measured and the change in those properties is evaluated. In this particular investigation the change in consistency as measured by the retained penetration is determined together with the mass loss due to volatilization. Table III presents the findings from this test. The clear binder shows a superior performance in terms of short-term aging compared to the conventional bitumen. A retained penetration of $61.2 \%$ is considered very good and higher than the normally minimum acceptable value of $+54 \%$ as per AASHTO M20-70 requirement. The mass loss from the clear binder is almost the same as the conventional bitumen and is significantly lower than the maximum acceptable value of $1.0 \%$ stated in AASHTO M20-70 for conventional bitumen. This clearly confirms that aging is not an issue for the clear binder under investigation.

\begin{tabular}{|l|c|c|}
\multicolumn{2}{c}{ TABLE III: AGING PERFORMANCE } \\
\hline Binder Type & Mass Loss $(\%)$ & $\begin{array}{c}\text { Retained Penetration }(\%) \\
\text { After RTFO Aging }\end{array}$ \\
\hline $\begin{array}{l}\text { Clear Binder } \\
\text { bonventional } \\
\text { bitumen }\end{array}$ & -0.051 & 61.2 \\
\hline
\end{tabular}

Asphalt binders are thermoplastic materials. Their 
consistency changes with temperature and hence the response to applied load when used in the asphalt mixture is also affected. Fig 4 shows the variation in viscosity of the clear binder and the conventional bitumen at different temperatures (temperature susceptibility). The temperature range was selected to encompass the normally used mixing and compaction temperatures in practice. As the temperature increases, the binder becomes less viscous. Knowing the temperature susceptibility of the binder being used in a paving mixture is important because it allows the determination of mixing and compaction temperatures.

Examining Fig 4, it is clear that the rate of change of viscosity with temperature is almost equal (lines are almost parallel) for both the conventional bitumen and the clear binder indicating a similar temperature susceptibility characteristics. Having a closer look at the data, it is clear that the clear binder has significantly higher viscosity values at all temperatures within the range used. For example, at temperature of $160^{\circ} \mathrm{C}$, Clear binder is about 11 times more viscous than the conventional bitumen, which makes compaction to the target air void levels extremely difficult and almost unachievable. It should be noted that traditionally, it is well established that the desired viscosity range for mixing is $0.17 \mathrm{~Pa} . \mathrm{s}$ and 0.28 Pa.s for compaction. The minimum viscosity for the clear binder is about $1.55 \mathrm{~Pa} . \mathrm{s}$ at $160{ }^{\circ} \mathrm{C}$ and that is much higher than the desired viscosity for mixing.

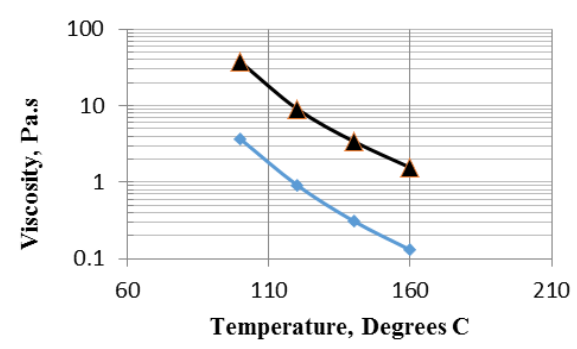

Fig. 4. Temperature susceptibility.

Several attempts were made to perform the ductility test as per AASHTO T51 standard. The extremely high consistency of the clear binder made it impossible to successfully complete the test. The test specimen was getting damaged at the ends of the briquettes due to the high stresses developed from trying to pull the binder as per the test standard procedure. This is indicative of low binder ductility. Fig 5 illustrates specimen failure during the test.

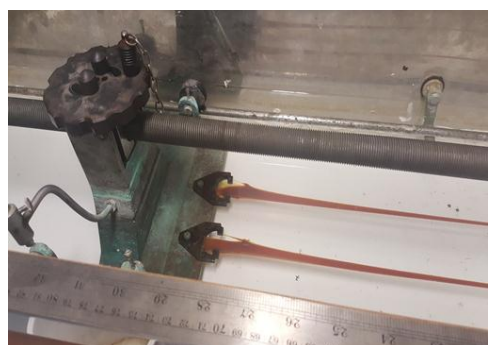

Fig. 5. Failure of ductility test at the ends of briquettes.

\section{CONCLUSIONS}

The results of this investigation showed that the tested clear binder is extremely viscous. It is harder than any bitumen grade specified by ASTM standards. Furthermore, the clear binder has much lower ductility compared to the conventional asphalt bitumen. The clear binder is almost 11 times more viscous than the conventional bitumen at the tested temperatures. This high viscosity makes compaction to the target air void levels extremely difficult and almost unachievable. Poor compaction of the pavement layer due to the use of excessively hard binder leads to high, interconnected void spaces that allow air to circulate in the mixture resulting in accelerated aging of the pavement layer. Additionally, with the daily thermal contraction and expansion, the hard, less ductile binder does not have the ability to absorb the shrinkage stresses developed and ultimately breaks, leading to the appearance of cracking on the surface.

\section{REFERENCES}

[1] G. D. Airey, M. H. Mohammed, and C. Fichter, "Rheological characteristics of synthetic road binders," Fuel, vol. 87, pp. 1763-1775, 2008.

[2] D. Lesueur, "The colloidal structure of bitumen: Consequences on the rheology and on the mechanism of bitumen modification," Advances in Colloid and Interface Science, vol. 145, pp. 42-82, 2009.

[3] P. Partal, F. J. Martinez-Boza, B. Conde, and C. Gallegos, "Rheological characterization of synthetic binders and unmodified bitumens," Fuel, vol. 78, pp. 1-10, 1999.

[4] M. A. Mewtlly and R. C. Williams, "Development of non-petroleum based binders for use in flexible pavements," Trans Project Reports, vol. 17, 2010

[5] M.A. Raouf, and R.C. Williams, "General physical and chemical properties of bio-binders derived from fast pyrolysis bio-oils", Proceedings of the 2010 Mid-Continent Transportation Research Forum, Madison (WI), USA, 2010.

[6] C. P Plug, and A.H.de Bondt, "Required mechanical properties of a clear binder for colored asphalt concrete". The 16th asphalt, pavement engineering and infrastructure conference, LJMU, Liverpool, UK, 2017.

[7] Maurizio Boccia, Andrea Grillib, Fabrizio Cardonea, Amedeo Virgilia, "Clear Asphalt Mixture for Wearing Course in Tunnels: Experimental Application in the Province of Bolzano" Procedia - Social and Behavioral Sciences vol. 53, pp 115-124, 2012.

[8] F.A. ,Santagata, F. Canestrari, G. Ferrotti, and A. Graziani, (2007), "Experimental characterization of transparent synthetic binder mixes reinforced with cellulose fibers". Proceedings of the 4th International SIIV Congress. Palermo, Italy, 2007.

[9] Lavin Patrick, "Asphalt Pavements: A Practical Guide to Design, Production and Maintenance for Engineers and Architects," 1st ed. Taylor \& Francis, Inc, 2003.

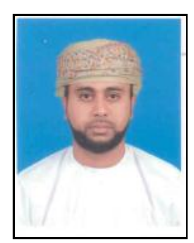

Khalid Al-Shamsi was born in Oman in 1969, graduated from Sultan Qaboos University, Civil engineering in 1993. He obtained his MSc in international highway engineering in 1995 from the university of Birmingham, UK, and obtained his $\mathrm{PhD}$ degree from Louisiana State University, USA in 2006. He is currently a faculty member at Sultan Qaboos University, Oman. His areas of research include characterization of bituminous materials, asphalt Mixture design methodologies, analytical gradation methods, use of recycled materials in asphalt pavements, warm Asphalt technology, traffic safety, and traffic crash analysis.

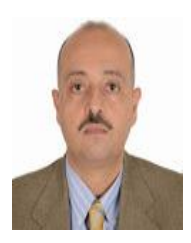

Hossam Abdelfattah was born on January 1969 graduated from Cairo University, Civil engineering with BSc honors in 1990. He obtained his MSc in 1993 from the same university, and obtained his $\mathrm{PhD}$ degree from Purdue University, West Lafayette in 1996. He is currently an Associate Professor at Sultan Qaboos University. His research interest is in pavement and roadway soil material testing and evaluation; performance-related testing and evaluation of asphalt concrete mixtures; recycling of waste and by-product materials in pavement material Environmental effect on pavement performance and maintenance and rehabilitation of pavements. 